nephron

Practice
Nephron 2016;132:86-92

DOI: $10.1159 / 000443314$
Received: November 10, 2015

Accepted after revision: December 10, 2015

Published online: February 4, 2016

\title{
Presence of Atrial Fibrillation at the Time of Dialysis Initiation Is Associated with Mortality and Cardiovascular Events
}

\author{
Akihito Tanaka Daijo Inaguma Hibiki Shinjo Minako Murata \\ Asami Takeda the Aichi Cohort Study of Prognosis in Patients Newly \\ Initiated into Dialysis (AICOPP) Study Group
}

Kidney Disease Center, Japanese Red Cross Nagoya Daini Hospital, Nagoya, Japan

\author{
Key Words \\ Dialysis · Chronic kidney disease - Atrial fibrillation · \\ Cardiovascular events · Mortality
}

\begin{abstract}
Background: Death in dialysis patients results mainly from cardiovascular and cerebrovascular diseases. To our knowledge, no prospective study has compared the rates of mortality or cardiovascular events between patients with and without atrial fibrillation (AF) at the time of dialysis initiation. Methods: This study included 1,516 patients who were initiated into dialysis between October 2011 and August 2013. Rates of mortality and cardiovascular events were compared between patients with and without $A F$, and between $A F$ patients with and without warfarin (WF) treatment. Results: The study comprised 1,025 men and 491 women with a mean age of $67.5 \pm 13.1$. Of these patients, 93 had AF, while 1,423 did not; $22.6 \%$ of the former group and $9.7 \%$ of the latter group died by March 2014 ( $p<0.01$ ). Cardiovascular events occurred in $34.4 \%$ of patients with AF and $15.1 \%$ of patients without $(p<0.01)$. Even after adjustments for various factors, AF remained an independent risk factor for mortality (hazard ratio (HR) 1.873, 95\% Cl 1.168-3.002, p < 0.01). It was also an independent risk factor for cardiovascular events (HR 1.872, 95\% Cl 1.262-2.778, p < 0.01). No differ-
\end{abstract}

ence in any parameter was noted between the groups that did and did not receive WF treatment. Conclusion: Patients with AF at the time of dialysis initiation show a poor prognosis and are at high risk of cardiovascular events. Therefore, AF should be taken into consideration in dialysis patients.

(c) 2016 S. Karger AG, Basel

\section{Introduction}

The number of patients receiving dialysis therapy is increasing every year, and these patients show high mortality from various causes, the main ones being cardiovascular diseases and cerebrovascular diseases (CVDs) [1]. Therefore, to improve the prognosis of patients initiated into dialysis therapy, it is important to understand the characteristics of those at high risk of mortality or CVDs. On the other hand, atrial fibrillation (AF), a cause of cerebral embolism, is highly prevalent in the elderly [2, 3], and AF patients have also been reported to be at high risk for CVDs [4]. Among maintenance dialysis patients, those with AF have been reported to show a poor prognosis $[5,6]$.

Studies assessing the efficacy and risk of warfarin (WF) in relation to prognosis and bleeding events in patients on maintenance dialysis and patients with chronic kidney

\section{KARGER}

E-Mail karger@karger.com

www.karger.com/nef
(C) 2016 S. Karger AG, Basel

$1660-8151 / 16 / 1322-0086 \$ 39.50 / 0$
Dr. Daijo Inaguma

Kidney Disease Center

Japanese Red Cross Nagoya Daini Hospital

2-9, Myoken-cho, Showa-ku, Nagoya 466-8650 (Japan)

E-Mail inaguma@nagoya2.jrc.or.jp 


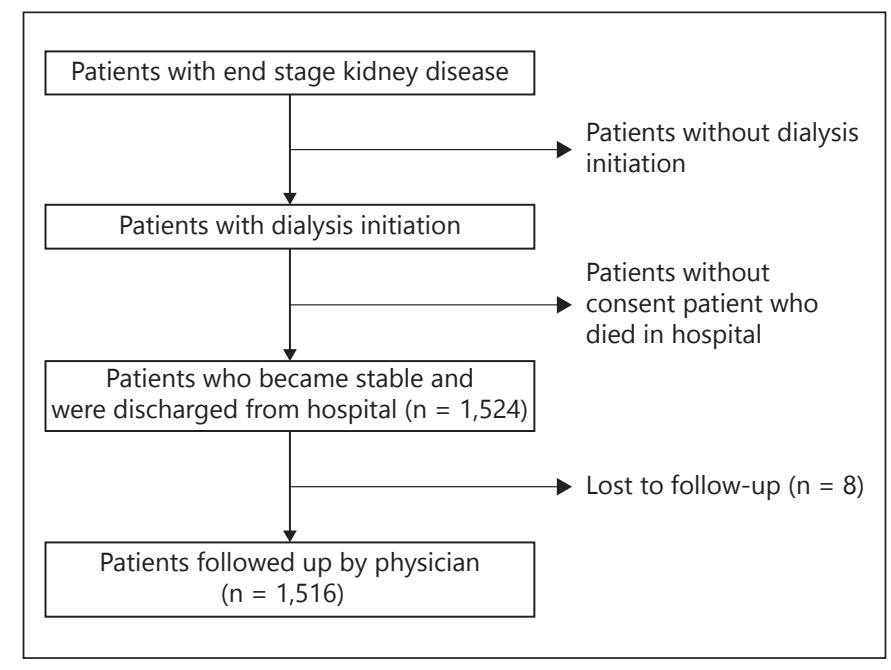

Fig. 1. Flowchart showing the process of patient registration. We included only those patients who became stable and were able to be discharged or transferred from hospital with consent. We excluded patients who were not able to be discharged and died in hospital.

disease (CKD) have yielded conflicting results. Therefore, it remains uncertain whether WF administration is favorable for dialysis or CKD patients [7-10]. However, no prospective report has compared mortality or cardiovascular events between patients initiated into dialysis therapy with or without AF. Thus, it remains to be determined how strongly AF is associated with mortality or CVDs in patients initiated into dialysis, and dialysis-related factors also need to be examined in relation to the presence of AF. In this study, we prospectively compared mortality and the incidence of CVDs between patients with $\mathrm{AF}$ at the time of dialysis initiation and those without AF.

\section{Patients and Methods}

Patient Registration and Data Collection

Data from the Aichi Cohort Study of Prognosis in Patients Newly Initiated into Dialysis [11] were used in this prospective, multicenter study that included patients initiated into dialysis between October 2011 and September 2013 at 17 Japanese institutions. The study was approved by the ethics committee of the Institutional Review Board of Nagoya Daini Red Cross Hospital (IRB20110823-3) and all patients provided written informed consent. We included only those patients who became stable and were able to be discharged or transferred from hospital; patients who were not able to be discharged and died in hospital were excluded. Figure 1 is a flowchart showing the process of patient registration. Data regarding patients' background, past history, comorbidity, medicines, laboratory data, and so on, during the period of dialysis

$\mathrm{AF}$ at Dialysis Initiation Is Associated with Mortality and CVD Events initiation were collected. The presence of AF was confirmed by electrocardiography on the first hospital day before the initiation of dialysis. Serological data and chest X-ray were obtained at the first dialysis session, just before its initiation. Cardiac ultrasonography was performed during hospitalization. Patients were followed up until the end of March 2014.

\section{Mortality and Cardiovascular Events}

Patients were divided into 2 groups, with or without AF, and the outcomes and hazard ratios (HRs) were assessed in these groups. The primary endpoint was mortality, while the secondary endpoint was CVDs, which included coronary artery disease (CAD), heart failure, stroke, peripheral artery disease, and aortic disease $(\mathrm{AD})$. CAD was defined as angiographically confirmed occlusion or stenosis of one or more coronary arteries, causing myocardial infarction or angina pectoris. Heart failure was defined as pulmonary congestion confirmed by radiograph, with hypoxemia that required hospital admission. Peripheral artery disease was defined as a disease that required admission for revascularization or amputation surgery. AD was defined as aortic aneurysm or dissection requiring surgery. The incidence of death and CVDs was investigated from survey slips that were sent to the dialysis facilities at the end of March 2014.

\section{Administration of WF}

AF patients were further divided into 2 groups: those that received WF treatment and those that did not. The incidence of death and CVDs was also investigated in these subgroups.

\section{Statistics}

Baseline characteristics were presented descriptively and tested using Student's $t$ test and the $\chi^{2}$ test. Survival was represented graphically using the Kaplan-Meier method and analyzed using univariate and multivariate Cox regression. HRs were represented graphically using forest plots. p values $<0.05$ were considered significant.

\section{Results}

\section{Baseline Characteristics}

The baseline characteristics of the patients are shown in table 1 . The initial population included 1,524 participants, of whom 1,032 were men and 492 were women, with a mean age of $67.5 \pm 13.1$. Eight patients who were untraceable were excluded. Of the remaining 1,516 patients, 93 had AF, while 1,423 did not. Patients in the AF group had a significantly higher mean age compared to those in the non-AF group $(72.1 \pm 10.4$ vs. $67.2 \pm 13.1$ years, respectively; $\mathrm{p}<0.001)$ and a significantly lower rate of angiotensin-converting enzyme inhibitor or angiotensin receptor blocker (ARB) treatment (44.8 vs. $61.1 \%$, respectively; $\mathrm{p}=0.002$ ). The prevalence of diabetes did not differ between patients with and without AF. In addition, although the former showed a high percentage of previous underlying conditions, such as CAD, heart 
Table 1. Baseline characteristics of patients with or without AF

\begin{tabular}{|c|c|c|c|}
\hline Parameter & $\begin{array}{l}\text { Patients } \\
\text { with AF }\end{array}$ & $\begin{array}{l}\text { Patients } \\
\text { without AF }\end{array}$ & $\mathrm{p}$ value \\
\hline Male, \% & 69.1 & 67.6 & 0.996 \\
\hline Age, years & $72.1 \pm 10.4$ & $67.2 \pm 13.1$ & $<0.001$ \\
\hline ACEi or ARB, \% & 44.8 & 61.1 & 0.002 \\
\hline Antiplatelet agent, \% & 33.0 & 30.2 & 0.573 \\
\hline WF, \% & 48.9 & 4.2 & $<0.001$ \\
\hline$\beta$-Blocker, $\%$ & 46.2 & 51.3 & 0.015 \\
\hline Statin, \% & 43.6 & 39.9 & 0.478 \\
\hline VDRA, \% & 23.4 & 27.3 & 0.414 \\
\hline Diabetes, \% & 51.1 & 51.1 & 0.996 \\
\hline History of CAD, \% & 28.7 & 15.0 & $<0.001$ \\
\hline History of PCI, \% & 16.0 & 9.8 & 0.054 \\
\hline History of CABG, \% & 4.3 & 4.3 & 0.987 \\
\hline History of HF admission, \% & 39.4 & 19.3 & $<0.001$ \\
\hline History of cerebral infarction, \% & 19.1 & 13.4 & 0.119 \\
\hline History of ICH, \% & 3.2 & 3.0 & 0.894 \\
\hline History of AD, \% & 10.6 & 5.2 & 0.026 \\
\hline History of PAD, F2, \% & 4.2 & 4.7 & 0.840 \\
\hline Amputation, \% & 3.2 & 1.5 & 0.225 \\
\hline Comorbid MI, \% & 8.5 & 5.7 & 0.260 \\
\hline Comorbid HF, \% & 51.1 & 23.8 & $<0.001$ \\
\hline Comorbid PAD, \% & 6.4 & 5.0 & 0.551 \\
\hline Comorbid stroke, \% & 13.8 & 8.7 & 0.094 \\
\hline Height, cm & $159.3 \pm 9.4$ & $159.5 \pm 9.5$ & 0.911 \\
\hline BMI, $\mathrm{kg} / \mathrm{cm}^{2}$ & $23.4 \pm 4.0$ & $23.5 \pm 4.4$ & 0.826 \\
\hline CTR, \% & $58.8 \pm 8.6$ & $54.2 \pm 9.2$ & $<0.001$ \\
\hline Hemoglobin, g/dl & $9.56 \pm 1.62$ & $9.36 \pm 1.55$ & 0.210 \\
\hline $\mathrm{ALB}, \mathrm{g} / \mathrm{dl}$ & $3.19 \pm 0.52$ & $3.20 \pm 0.60$ & 0.862 \\
\hline $\mathrm{eGFR}, \mathrm{ml} / \mathrm{min} / 1.7 \mathrm{~m}^{2}$ & $6.34 \pm 2.79$ & $5.39 \pm 2.17$ & $<0.001$ \\
\hline $\mathrm{Na}, \mathrm{mEq} / \mathrm{l}$ & $137.6 \pm 4.6$ & $137.9 \pm 4.4$ & 0.496 \\
\hline $\mathrm{K}, \mathrm{mEq} / \mathrm{l}$ & $4.43 \pm 0.81$ & $4.56 \pm 0.84$ & 0.120 \\
\hline $\mathrm{cCa}, \mathrm{mg} / \mathrm{dl}$ & $8.72 \pm 0.95$ & $8.61 \pm 1.06$ & 0.303 \\
\hline $\mathrm{P}, \mathrm{mg} / \mathrm{dl}$ & $5.97 \pm 1.73$ & $6.39 \pm 1.89$ & 0.038 \\
\hline $\mathrm{Mg}, \mathrm{mg} / \mathrm{dl}$ & $2.12 \pm 0.42$ & $2.15 \pm 0.49$ & 0.558 \\
\hline ALP, U/l & $263.2 \pm 99.8$ & $264.8 \pm 176.7$ & 0.932 \\
\hline LVEF, \% & $55.3 \pm 16.1$ & $61.0 \pm 12.0$ & $<0.001$ \\
\hline Death, \% & 22.6 & 9.7 & $<0.001$ \\
\hline CVD, \% & 34.4 & 15.1 & $<0.001$ \\
\hline
\end{tabular}

$\mathrm{ACEi}=$ Angiotensin-converting enzyme inhibitor VDRA $=$ vitamin $\mathrm{D}$ receptor agonist $\mathrm{PCI}=$ percutaneous coronary intervention $; \mathrm{CABG}=$ coronary artery bypass grafting; PAD, F2 = peripheral arterial disease with Fontaine classification 2-4; $\mathrm{MI}=$ myocardial infarction; $\mathrm{BMI}=$ body mass index; $\mathrm{CTR}=$ cardiothoracic ratio; $\mathrm{ALB}=$ albumin $\mathrm{Na}=$ sodium; $\mathrm{K}=$ potassium; $\mathrm{cCa}=$ corrected calcium; $\mathrm{P}=$ phosphate; $\mathrm{Mg}=$ magnesium; $\mathrm{ALP}=$ alkaline phosphatase; $L V E F=$ left ventricular ejection fraction.

failure admission, and $\mathrm{AD}$, the groups did not differ significantly in terms of the incidence of cerebral infarction or intracerebral hemorrhage (ICH). The estimated glomerular filtration rate (eGFR) [12] was significantly higher in AF patients than in non-AF patients $(6.34 \pm 2.79$ vs. $5.39 \pm 2.17 \mathrm{ml} / \mathrm{min} / 1.7 \mathrm{~m}^{2}$, respectively; $\left.\mathrm{p}<0.001\right)$.

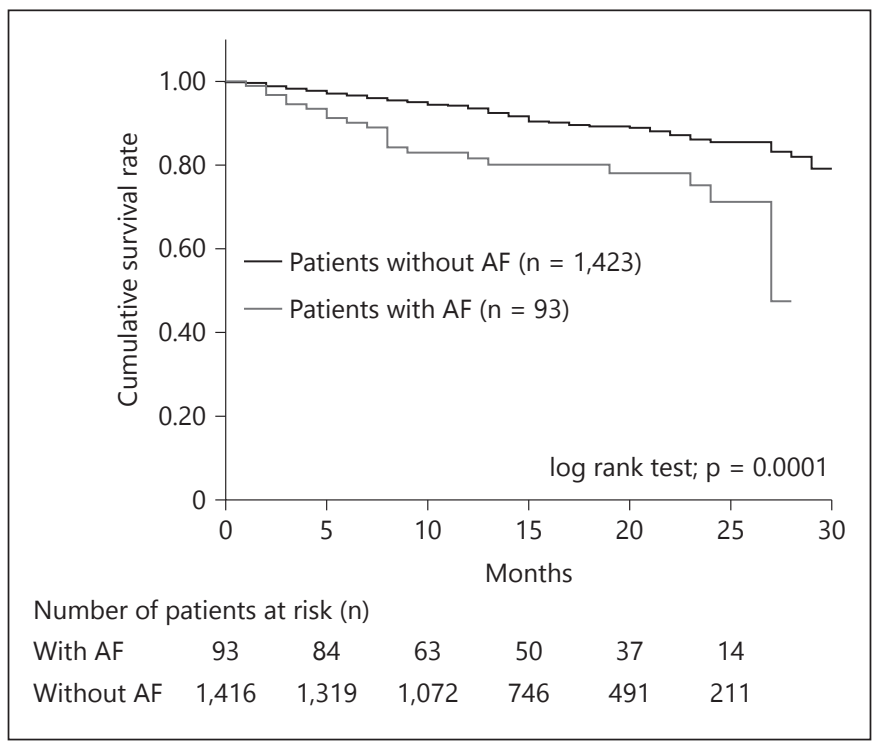

Fig. 2. Kaplan-Meier plot of survival in patients with or without AF.

\section{Mortality and CVDs in Patients with or without AF}

The median follow-up period was 15 months. During follow-up, 159 patients died from various causes, including cardiogenic events (28 patients, 17.6\%), infectious disease (28 patients, $17.6 \%$ ), cancer (21 patients, $13.2 \%$ ), intracranial hemorrhage ( 9 patients, $5.7 \%$ ), peripheral artery disease (6 patients, $3.8 \%$ ), cerebral infarction (3 patients, $1.9 \%), \mathrm{AD}$ (2 patients, $1.3 \%$ ), other causes (16 patients, $10.1 \%$ ), and unknown causes (46 patients, $28.9 \%$ ). Figure 2 shows a Kaplan-Meier plot for mortality in the groups with and without AF. The former group had a significantly higher mortality rate than the latter $(22.6 \%$ (21 patients) vs. $9.7 \%$ (138 patients), respectively; $\mathrm{p}<0.01$; table 1). Figure 3 presents a forest plot showing the HRs of AF for death adjusted for various factors. Multivariable adjustment for cofactors showed that $\mathrm{AF}$ was an independent risk factor for death (HR 1.873, 95\% CI 1.168-3.002, $\mathrm{p}<0.01)$. CVDs developed in 246 patients and included CAD (82 patients, $33.3 \%$ ), heart failure requiring admission (73 patients, $29.7 \%)$, cerebral infarction (29 patients, $11.8 \%)$, peripheral artery disease (19 patients, $7.7 \%), \mathrm{AD}$ (18 patients, $7.3 \%$ ), intracranial hemorrhage (15 patients, $6.1 \%$ ), and others (15 patients, $6.1 \%$ ). The above data include some cases of overlap. The term 'others' refers to cases, such as CAD or heart failure, which were difficult to diagnose precisely. A Kaplan-Meier plot for CVDs in the groups with and without $\mathrm{AF}$ is shown in figure 4. Consistently with the results for mortality, AF patients showed a significantly higher incidence of CVDs than those with- 


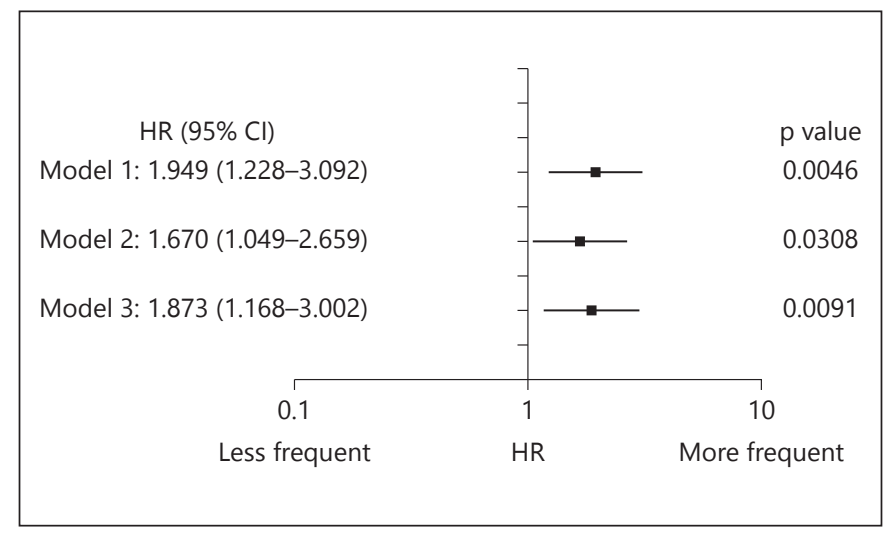

Fig. 3. HRs of AF for death. Model 1 is adjusted for age and sex. Model 2 is adjusted by inclusion of administration of angiotensinconverting enzyme or $\mathrm{ARB}$, diabetes, history of $\mathrm{CAD}$, heart failure, and AD, and eGFR in Model 1. Model 3 is adjusted by inclusion of $\beta$-blocker administration, hemoglobin levels, corrected calcium levels, phosphate levels, and history of cerebral infarction and $\mathrm{ICH}$ in Model 2.

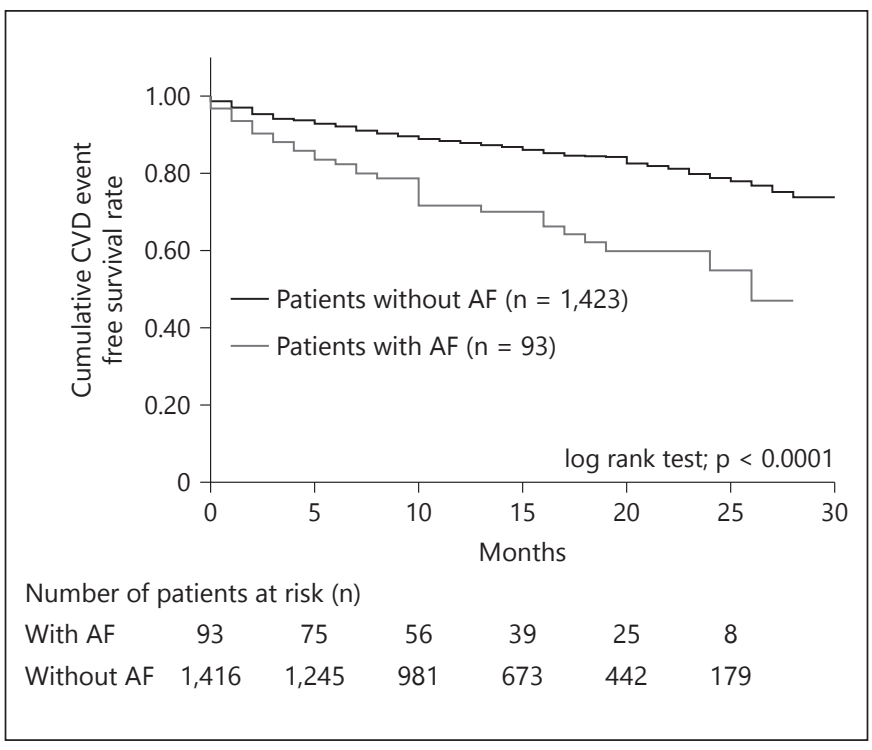

Fig. 4. Kaplan-Meier plot of CVD-free survival rate in patients with or without AF.

out $\mathrm{AF}$ (34.4\% (32 patients) vs. $15.1 \%$ (214 patients), respectively; $\mathrm{p}<0.01$; table 1 ). Additionally, from the forest plot showing the HRs of AF for CVDs adjusted for various factors (fig. 5), it can be seen that AF was an independent risk factor for CVDs (HR 1.872, 95\% CI 1.262-2.778, $\mathrm{p}<0.01)$. Thus, patients with AF at the time of dialysis initiation had significantly higher mortality and incidence of CVDs than those without AF.

$\mathrm{AF}$ at Dialysis Initiation Is Associated with Mortality and CVD Events

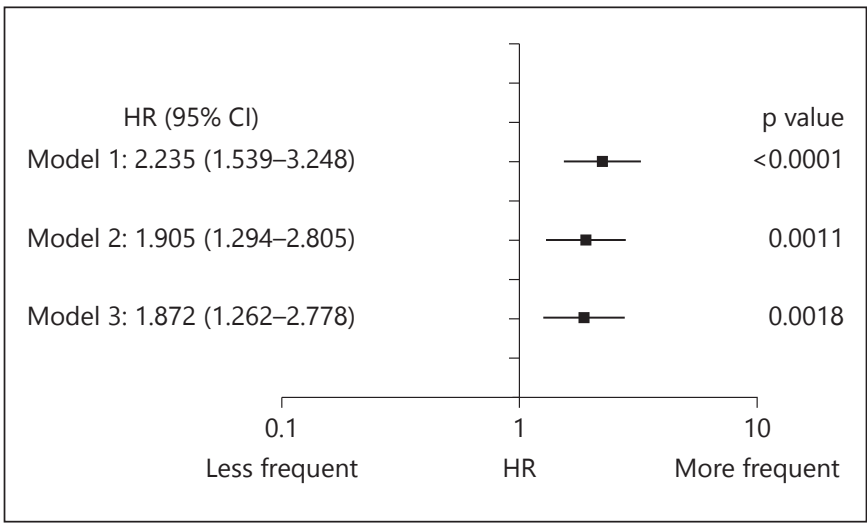

Fig. 5. HRs of AF for CVDs. Model 1 is adjusted for age and sex. Model 2 is adjusted by inclusion of administration of angiotensinconverting enzyme or $\mathrm{ARB}$, diabetes, history of CAD, heart failure, and $\mathrm{AD}$, hemoglobin levels, administration of antiplatelet agent, and eGFR in Model 1. Model 3 is adjusted by inclusion of $\beta$-blocker administration, corrected calcium levels, phosphate levels, and history of cerebral infarction and ICH in Model 2.

\section{Mortality and CVDs in AF Patients with or without WF Treatment}

Among the 93 patients with AF, 46 were under treatment with WF, while 47 were not. Table 2 shows the characteristics of these patient subgroups. No significant differences were observed between the groups in age, sex, or percentage of past cerebral infarction or ICH. The eGFR also showed no significant between-group differences. Importantly, mortality and the incidence of CVDs did not differ significantly between the groups with and without WF treatment (mortality: 23.9\% (11 patients) vs. $21.3 \%$ (10 patients), respectively; $\mathrm{p}=0.761$; fig. 6) (CVDs: $32.6 \%$ (15 patients) vs. $36.2 \%$ (17 patients), respectively; $\mathrm{p}=0.718$; fig. 7). The CVDs included cerebral infarction and $\mathrm{ICH}$. The incidence of cerebral infarction did not differ significantly between the groups with and without WF (4.3\% (2 patients) in both groups; $\mathrm{p}=0.982$; online suppl. fig. 1, see www.karger.com/doi/10.1159/000443314). Nor did the incidence of ICH differ between the groups with and without WF in patients with AF (no patients in either subgroup).

\section{Discussion}

The results of this study showed that patients with $\mathrm{AF}$ at the time of dialysis initiation had significantly higher mortality and incidence of CVDs than those without AF. Thus, special attention needs to be paid to 
Table 2. Baseline characteristics of AF patients with or without WF

\begin{tabular}{|c|c|c|c|}
\hline Parameter & $\begin{array}{l}\text { Patients } \\
\text { with WF }\end{array}$ & $\begin{array}{l}\text { Patients } \\
\text { without WF }\end{array}$ & $\mathrm{p}$ value \\
\hline Male, \% & 73.9 & 66.0 & 0.403 \\
\hline Age, years & $73.6 \pm 8.5$ & $70.7 \pm 12.1$ & 0.184 \\
\hline ACEi or ARB, $\%$ & 50.0 & 48.9 & 0.918 \\
\hline Antiplatelet agent, \% & 32.6 & 34.0 & 0.883 \\
\hline$\beta$-Blocker, $\%$ & 58.7 & 33.3 & 0.014 \\
\hline Statin, \% & 50.0 & 50.0 & 0.256 \\
\hline VDRA, \% & 26.1 & 21.3 & 0.585 \\
\hline Diabetes, \% & 45.7 & 57.4 & 0.255 \\
\hline History of CAD, \% & 32.6 & 25.5 & 0.452 \\
\hline History of PCI, \% & 19.6 & 12.8 & 0.372 \\
\hline History of CABG, \% & 6.5 & 2.1 & 0.296 \\
\hline History of HF admission, \% & 43.5 & 36.2 & 0.472 \\
\hline History of cerebral infarction, \% & 23.9 & 14.9 & 0.271 \\
\hline History of ICH, \% & 6.5 & 0.0 & 0.075 \\
\hline History of $\mathrm{AD}, \%$ & 10.9 & 10.6 & 0.971 \\
\hline History of PAD, F2, \% & 2.2 & 6.4 & 0.317 \\
\hline Amputation, $\%$ & 2.2 & 4.3 & 0.570 \\
\hline Comorbid MI, \% & 8.7 & 8.5 & 0.975 \\
\hline Comorbid HF, \% & 47.8 & 55.3 & 0.470 \\
\hline Comorbid PAD, \% & 2.2 & 10.6 & 0.097 \\
\hline Comorbid stroke, $\%$ & 19.6 & 8.5 & 0.124 \\
\hline Height, cm & $159.4 \pm 10.2$ & $159.3 \pm 8.7$ & 0.975 \\
\hline $\mathrm{BMI}, \mathrm{kg} / \mathrm{cm}^{2}$ & $23.7 \pm 4.3$ & $23.1 \pm 3.8$ & 0.588 \\
\hline CTR, \% & $60.0 \pm 5.8$ & $57.7 \pm 10.8$ & 0.199 \\
\hline Hemoglobin, g/dl & $9.76 \pm 1.62$ & $9.30 \pm 1.55$ & 0.172 \\
\hline $\mathrm{ALB}, \mathrm{g} / \mathrm{dl}$ & $3.31 \pm 0.45$ & $3.06 \pm 0.56$ & 0.018 \\
\hline $\mathrm{eGFR}, \mathrm{ml} / \mathrm{min} / 1.7 \mathrm{~m}^{2}$ & $6.70 \pm 3.03$ & $6.05 \pm 2.52$ & 0.272 \\
\hline $\mathrm{Na}, \mathrm{mEq} / \mathrm{l}$ & $137.9 \pm 4.9$ & $137.4 \pm 4.4$ & 0.637 \\
\hline $\mathrm{K}, \mathrm{mEq} / \mathrm{l}$ & $4.53 \pm 0.81$ & $4.34 \pm 0.80$ & 0.261 \\
\hline $\mathrm{cCa}, \mathrm{mg} / \mathrm{dl}$ & $8.72 \pm 0.90$ & $8.78 \pm 0.98$ & 0.760 \\
\hline $\mathrm{P}, \mathrm{mg} / \mathrm{dl}$ & $5.41 \pm 1.69$ & $6.44 \pm 1.59$ & 0.004 \\
\hline $\mathrm{Mg}, \mathrm{mg} / \mathrm{dl}$ & $2.06 \pm 0.50$ & $2.18 \pm 0.33$ & 0.294 \\
\hline ALP, U/l & $248.4 \pm 113.1$ & $277.9 \pm 85.0$ & 0.172 \\
\hline LVEF, \% & $56.7 \pm 15.1$ & $53.9 \pm 16.9$ & 0.458 \\
\hline Death, \% & 23.9 & 21.3 & 0.761 \\
\hline CVD, \% & 32.6 & 36.2 & 0.718 \\
\hline
\end{tabular}

ACEi = Angiotensin-converting enzyme inhibitor; VDRA = vitamin D receptor agonist; $\mathrm{PCI}=$ percutaneous coronary intervention; $\mathrm{CABG}=$ coronary artery bypass grafting; PAD, F2 = peripheral arterial disease with Fontaine classification 2-4; $\mathrm{MI}=$ myocardial infarction; $\mathrm{BMI}=$ body mass index; $\mathrm{CTR}=$ cardiothoracic ratio; $\mathrm{ALB}=$ albumin; $\mathrm{Na}=$ sodium; $\mathrm{K}=$ potassium; $\mathrm{cCa}=$ corrected calcium; $\mathrm{P}=$ phosphate; $\mathrm{Mg}=$ magnesium; $\mathrm{ALP}=$ alkaline phosphatase; LVEF = left ventricular ejection fraction.

prevent death and CVDs in these patients. We also investigated the efficacy of WF for AF patients in this population and found no differences in the rates of mortality or CVDs between patients who did or did not receive WF treatment. However, this finding could be attributable to the relatively small number of patients examined.

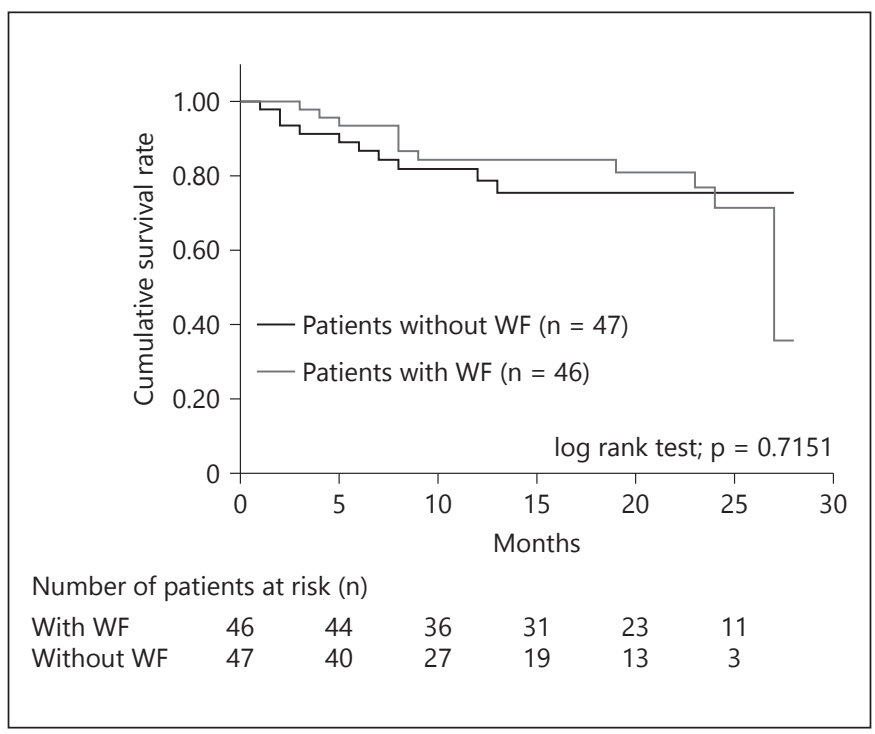

Fig. 6. Kaplan-Meier plot of survival in AF patients with or without WF treatment.

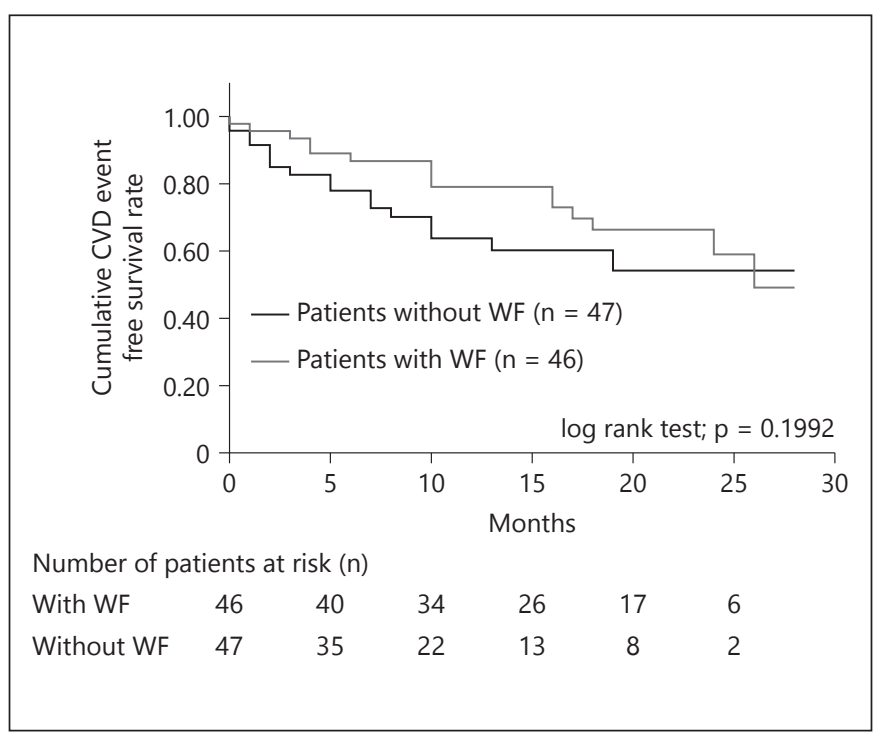

Fig. 7. Kaplan-Meier plot of CVD-free survival rate in AF patients with or without WF treatment.

Previous reports showed that AF was prevalent in patients with CKD, who had a poor prognosis. Further, AF patients on maintenance dialysis were also reported to have a poor prognosis $[9,13,14]$. Additionally, there is a study similar to ours that included patients from the time of dialysis initiation and recorded mortality and CVDs [15]. Because the study revealed high rates of mortality 
and CVDs at an early stage (within the first week) of dialysis initiation, their population seems to have been different from ours. Our study included only those patients who became stable and were able to be discharged or transferred from hospital. Hence, to our knowledge, no prospective report has considered the AF status of stable discharged patients from the time of dialysis initiation to determine the prognosis of AF patients. Additionally, no previous report has shown the association between the presence of $\mathrm{AF}$ at the time of dialysis initiation and CVDs in a population like that of this study. The main contribution of our study is that it is the first to cover these points of investigation.

Several previous studies have assessed the efficacy and risk of WF for patients with AF. Some analyzed whether WF is effective for the prevention of cerebral embolism and improving prognosis in dialysis patients, or whether it should be avoided because of the increased bleeding risk. Similarly, some studies analyzed whether or not WF is effective for preventing cerebral embolism and improving prognosis in CKD patients with AF. At present, these reports have not been able to reach a consensus on the effects of WF $[3,10,16,17]$. Our results, too, were inconclusive as to whether WF is useful for patients with $\mathrm{AF}$ at the time of dialysis initiation.

We found that the rates of mortality and CVDs were twice as high in patients with AF as in those without. This could be related to the association of AF with cerebral embolism. Furthermore, the presence of AF itself suggests underlying heart problems, and patients with an underlying heart disease are inevitably susceptible to CVDs. WF was probably not efficacious in the AF patients because of the bleeding tendency in patients with renal failure $[18,19]$. Although WF prevents cerebral embolism, it is associated with bleeding complications such as $\mathrm{ICH}$ and gastrointestinal bleeding. Unfortunately, in this study, we were not able to assess individual CVDs, such as cerebral infarction, embolism, and ICH, completely. Furthermore, the small number of patients with AF may have resulted in lack of sufficient statistical power to prove a reduced benefit or adverse effect.

Our study has some limitations. First, although we examined patients who had AF at the time of dialysis initiation, we did not ascertain whether the AF was paroxysmal or chronic. Further, we did not determine whether the AF was being treated or whether it was due to the valvular disease. There are also many cases with an unknown cause of death. This seems to have been due to patients' being transported to other hospitals for an acute disease, rather than the one in which they were usually treated.

\section{Conclusion}

Patients who have AF at the time of dialysis initiation show high rates of mortality and CVDs. Physicians should be aware of this tendency and take it into consideration when treating such patients. Further, more detailed studies are needed to refine our understanding of the relation between $\mathrm{AF}$ and adverse events in patients undergoing dialysis.

\section{Acknowledgments}

We acknowledge the support of the following members of the Aichi cohort study of prognosis in patients newly initiated into dialysis (AICOPP), who participated in this study: Hirofumi Tamai (Anjo Kosei Hospital), Tomohiko Naruse (Kasugai Municipal Hospital), Kei Kurata (Tosei General Hospital), Hideto Oishi (Komaki City Hospital), Isao Aoyama (Japan Community Healthcare Organization Chukyo Hospital), Hiroshi Ogawa (Shinseikai Daiichi Hospital), Hiroko Kushimoto (Nishichita General Hospital), Hideaki Shimizu (Chubu-Rosai Hospital), Junichiro Yamamoto (Tsushima City Hospital), Hisashi Kurata (Toyota Kosei Hospital), Taishi Yamakawa (Toyohashi Municipal Hospital), Takaaki Yaomura (Nagoya Medical Center), Hirotake Kasuga (Nagoya Kyouritsu Hospital), Shizunori Ichida (Japanese Red Cross Nagoya Daiichi Hospital), Shoichi Maruyama (Nagoya University Graduate School of Medicine), Noritoshi Kato (Nagoya University Graduate School of Medicine), Seiichi Matsuo (Nagoya University Graduate School of Medicine), Shigehisa Koide (Fujita Health University Hospital), and Yukio Yuzawa (Fujita Health University Hospital).

\section{Disclosure Statement}

None.

References

1 Nakai S, Hanafusa N, Masakane I, Taniguchi M, Hamano T, Shoji T, Hasegawa T, Itami N, Yamagata K, Shinoda T, Kazama JJ, Watanabe Y, Shigematsu T, Marubayashi S, Morita O, Wada A, Hashimoto S, Suzuki K, Nakamoto H, Kimata N, Wakai K, Fujii N, Ogata S, Tsuchida K, Nishi H, Iseki K, Tsubakihara Y: An overview of regular dialysis treatment in Japan (as of 31 December 2012). Ther Apher Dial 2014;18: 535-602.

-2 JCS Joint Working Group: Guidelines for pharmacotherapy of atrial fibrillation (JCS 2013). Circ J 2014;78:1997-2021.

-3 Olesen JB, Lip GY, Kamper AL, Hommel K, Køber L, Lane DA, Lindhardsen J, Gislason GH, Torp-Pedersen C: Stroke and bleeding in atrial fibrillation with chronic kidney disease. N Engl J Med 2012;367:625-635. 
4 Ezekowitz MD, Netrebko PI: Anticoagulation in management of atrial fibrillation. Curr Opin Cardiol 2003;18:26-31.

$>5$ Benjamin EJ, Wolf PA, D’Agostino RB, Silbershatz H, Kannel WB, Levy D: Impact of atrial fibrillation on the risk of death: the Framingham heart study. Circulation 1998;98:946-952.

$\checkmark 6$ Kannel WB, Abbott RD, Savage DD, McNamara PM: Epidemiologic features of chronic atrial fibrillation: the Framingham study. N Engl J Med 1982;306:1018-1022.

7 Carrero JJ, Evans M, Szummer K, Spaak J, Lindhagen L, Edfors R, Stenvinkel P, Jacobson SH, Jernberg T: Warfarin, kidney dysfunction, and outcomes following acute myocardial infarction in patients with atrial fibrillation. JAMA 2014;311:919-928.

$>8$ Lai HM, Aronow WS, Kalen P, Adapa S, Patel K, Goel A, Vinnakota R, Chugh S, Garrick R: Incidence of thromboembolic stroke and of major bleeding in patients with atrial fibrillation and chronic kidney disease treated with and without warfarin. Int J Nephrol Renovasc Dis 2009;2:33-37.

$>9$ Wizemann V, Tong L, Satayathum S, Disney A, Akiba T, Fissell RB, Kerr PG, Young EW, Robinson BM: Atrial fibrillation in hemodialysis patients: clinical features and associations with anticoagulant therapy. Kidney Int 2010;77:1098-1106.
10 Friberg L, Benson L, Lip GY: Balancing stroke and bleeding risks in patients with atrial fibrillation and renal failure: the Swedish atrial fibrillation cohort study. Eur Heart J 2015;36: 297-306.

11 Sueta S, Morozumi K, Takeda A, Horike K, Otsuka Y, Shinjo H, Murata M, Kato Y, Goto K, Inaguma D; Aichi Cohort Study of Prognosis in Patients Newly Initiated Into Dialysis (AICOPP) Study Group: Ability of vitamin D receptor activator to prevent pulmonary congestion in advanced chronic kidney disease. Clin Exp Nephrol 2015;19:371-378.

12 Matsuo S, Imai E, Horio M, Yasuda Y, Tomita K, Nitta K, Yamagata K, Tomino Y, Yokoyama H, Hishida A: Revised equations for estimated GFR from serum creatinine in Japan. Am J Kidney Dis 2009;53:982-992.

13 Soliman EZ, Prineas RJ, Go AS, Xie D, Lash JP, Rahman M, Ojo A, Teal VL, Jensvold NG, Robinson NL, Dries DL, Bazzano L, Mohler ER, Wright JT, Feldman HI: Chronic kidney disease and prevalent atrial fibrillation: the chronic renal insufficiency cohort (CRIC). Am Heart J 2010;159:1102-1107.

14 Atar I, Konaş D, Açikel S, Külah E, Atar A, Bozbaş H, Gülmez O, Sezer S, Yildirir A, Ozdemir N, Müderrisoğlu H, Ozin B: Frequency of atrial fibrillation and factors related to its development in dialysis patients. Int J Cardiol 2006;106:47-51.
5 Eckardt KU, Gillespie IA, Kronenberg F, Richards S, Stenvinkel P, Anker SD, Wheeler DC, de Francisco AL, Marcelli D, Froissart M, Floege J; ARO Steering Committee: High cardiovascular event rates occur within the first weeks of starting hemodialysis. Kidney Int 2015;88:1117-1125.

16 Chan KE, Lazarus JM, Thadhani R, Hakim RM: Warfarin use associates with increased risk for stroke in hemodialysis patients with atrial fibrillation. J Am Soc Nephrol 2009;20: 2223-2233.

17 Shah M, Avgil Tsadok M, Jackevicius CA, Essebag V, Eisenberg MJ, Rahme E, Humphries $\mathrm{KH}, \mathrm{Tu}$ JV, Behlouli H, Guo H, Pilote L: Warfarin use and the risk for stroke and bleeding in patients with atrial fibrillation undergoing dialysis. Circulation 2014;129: 1196-1203.

18 Yang JY, Lee TC, Montez-Rath ME, Paik J, Chertow GM, Desai M, Winkelmayer WC: Trends in acute nonvariceal upper gastrointestinal bleeding in dialysis patients. J Am Soc Nephrol 2012;23:495-506.

-19 Iseki K, Kinjo K, Kimura Y, Osawa A, Fukiyama K: Evidence for high risk of cerebral hemorrhage in chronic dialysis patients. Kidney Int 1993;44:1086-1090. 